\title{
Pathological and immunological characteristics of piglets infected experimentally with a HP-PRRSV TJ strain
}

\author{
Zhenguang $\mathrm{Li}^{1,2+}$, Yanliang $\mathrm{He}^{1 \dagger}$, Xiaoqin $\mathrm{Xu}^{3}$, Xue Leng ${ }^{2}$, Shufen $\mathrm{Li}^{1}$, Yongjun Wen², Fengxue Wang ${ }^{2}$, Mingqi Xia', \\ Shipeng Cheng ${ }^{2}$ and Hua $\mathrm{Wu}^{1,2^{*}}$
}

\begin{abstract}
Background: Porcine reproductive and respiratory syndrome (PRRS) remains a major threat to swine industry all over the world. The aim of this study was to investigate the mechanism of pathogenesis and immune responses caused by a highly pathogenic porcine reproductive and respiratory syndrome virus (HP-PRRSV).

Results: All piglets experimentally infected with a HP-PRRSV TJ strain virus developed typical clinical signs of PRRS. The percentages of $\mathrm{CD}^{+}, \mathrm{CD}^{+}$, and $\mathrm{CD}^{+}$lymphocytes significantly decreased in the infected group as compared to the uninfected control animals $(p<0.01)$. Total WBC dropped in the infected animals during the experiment. The level of ELISA antibody against PRRSV increased in 7-10 days after infection and then started to decline.

Pathological observations demonstrated various degree lesions, bleeding and necrosis in the lungs of the infected piglets.

Conclusions: These results clearly indicated that HP-PRRSV TJ strain infection would activate host humoral immune response at the early period post infection and cause severe pathological damages on lungs and inhibit cellular immune response after infection.
\end{abstract}

Keywords: HP-PRRSV, humoral immunity, cell-mediated immunity, immune responses

\section{Background}

Porcine reproductive and respiratory syndrome (PRRS) is characterized by reproductive failure in pregnant sows and respiratory distress in pigs of all ages [1]. The disease was first reported in the United States in 1987 and later in the Netherlands and other parts of the world [2]. The PRRS virus (PRRSV) is an enveloped positivestranded RNA virus which belongs to the family of Arteriviridae in the order of the Nidovirales. Other related viruses of family Arteriviridae include equine arterutus virus, lactate dehydrogenase-elevating virus and simian haemorrhagic fever virus [3].

\footnotetext{
*Correspondence: wuhua@sinovetah.com

${ }^{\dagger}$ Equal contributors

${ }^{1}$ Sinovet (Beijing) Biotechnology Co., Ltd., Kaituo Road 5, Haidian District, Beijing 100085, China

${ }^{2}$ State Key Laboratory of Special Economic Animal Molecular Biology, Institute of Special Economic Animal and Plant Sciences, Chinese Academy of Agricultural Sciences, Juye Street 4899, Changchun, Jilin 130122, China Full list of author information is available at the end of the article
}

PRRSV mainly replicates in alveolar macrophages in the lungs and lymphoid organs [4]. Thus, the potential for aerosol spread through respiratory and oropharyngeal excretions within swine confinement units is a distinct possibility. The virus is well- known to stay in lungs and lymphoid organs of infected pigs for a long time. It was reported that an infected sow was able to transmit PRRSV up to 157 days post initial infection [5]. Others had detected PRRSV in lymph organs up to 132 days when the piglets were infected in the uterus [6]. PRRSV was also detected more than 180 days postinfection [7]. The mechanism of PRRSV persistence is not completely understood but is likely related to the emergence of viral variants which can escape host immune response [8].

PRRS has now emerged as the most prevalent disease of swine in the world. In the United States, annual loss due to PRRS is estimated at 560 million dollars [9]. In early 2006 , a highly pathogenic disease emerged in some 
swine farms in Jiangxi province of China, and then spread rapidly to the rest of China [10]. This disease remains a major threat to swine industry all over the world [11]. Infected pigs of all ages presented with clinical signs including continuous high fever of above $41{ }^{\circ} \mathrm{C}$, depression, dyspnea, anorexia, red discoloration of the ears and skin, conjunctivitis, mild diarrhea, shivering and limping. The morbidity rate was $50-100 \%$ with mortality rate of $20-100 \%$ [12]. Studies demonstrated that highly pathogenic porcine reproduction and respiratory syndrome virus (HP-PRRSV) was the major pathogen that caused the outbreak. HP-PRRSV TJ strain was originally isolated from a piglet that died of a "high fever" in Tianjin, China, in 2006, and it had the same characteristics as those of other HP-PRRSV strains observed in China. HPPRRSV strain TJ was culturally passaged on MARC-145 cells for attenuation so that it could be used for the development of a modified live virus (MLV) vaccine [13]. Genetic analysis indicates that the HP-PRRSV isolated from China has a discontinuous deletion of 30 amino acids (AA) in non-structural protein 2 (Nsp2), compared with the North American type of PRRSV strain. However, the mechanisms contributing to the molecular pathogenesis of the HP-PRRSV have not been elucidated.

Some preliminary studies reported that PRRSV modulates the host immune responses and alters host gene expression [14-17]. In order to further investigate the immunological characteristics of HP-PRRSV, ten fiveweek-old pigs were experimentally infected with HPPRRSV TJ strain and pathological changes, humoral and cell-mediated immune responses were evaluated in the present study.

\section{Results}

\section{Clinical signs observations post infection}

All piglets infected with HP-PRRSV TJ strain virus developed typical clinical signs of HP-PRRS, such as severe depression and anorexia, lameness and shivering, dyspnea, skin cyanosis and death. Four of five PRRSVinfected piglets died of acute respiratory disease. Conversely, no clinical signs were observed in the control ones. Infected animals had persistently high fever $\left(\geq 41^{\circ}\right.$ C) at 4 day post infection (dpi), which lasted 9 days (Fig. 1a). In contrast, control piglets remained healthy with normal body temperature throughout the experiment. Animals in group 1 showed significantly higher average clinical scores than the control group $(<0.01)$ (Fig. 1b). As shown in Fig. 1c, animals infected with HPPRRSV TJ strain in group 1 lost significantly more body weight than those in control group.

\section{Gross pathology and histological evaluations of lungs}

No macroscopic (gross) lesions were recorded in the lungs collected from the control animals at necropsy

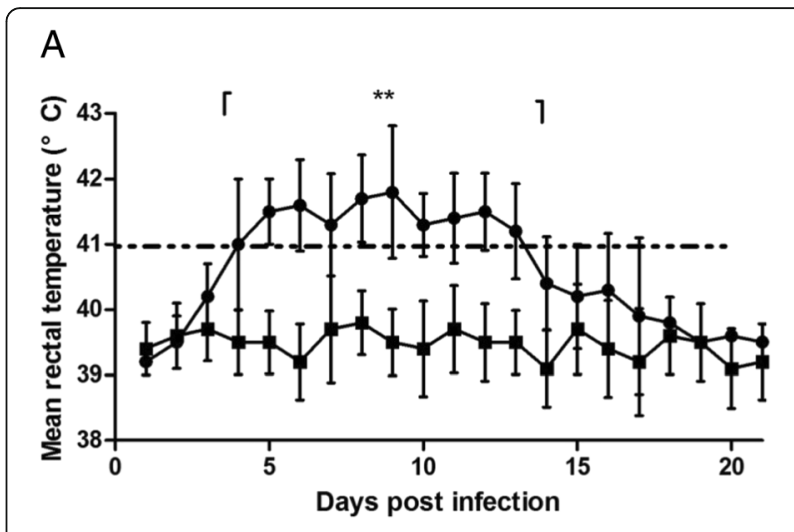

B

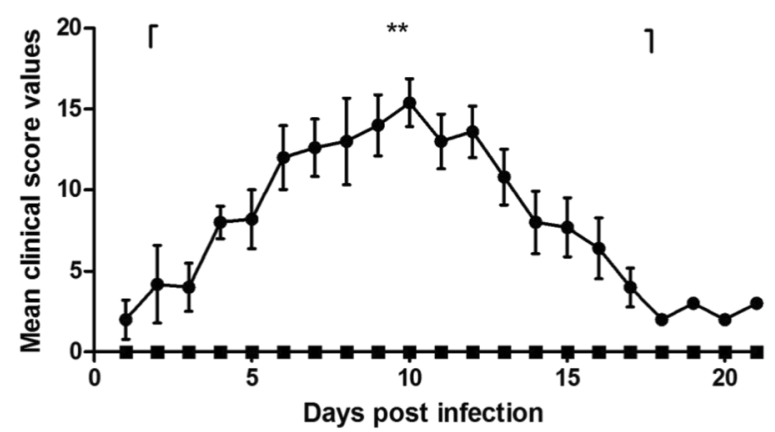

C

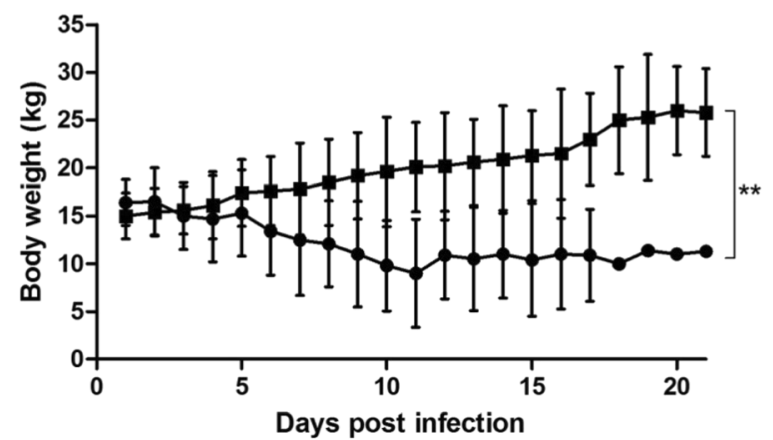

- Control

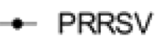

Fig. 1 Clinical evaluation for each piglet post infection. After infection, mean rectal temperatures (a), mean clinical score (b) and body weight (c) of each animal were measured daily in HP-PRRSV inoculation group (PRRSV, $n=5$ ) and control group (Control, $n=5$ ). Rectal temperatures equal or above $41^{\circ} \mathrm{C}\left(\geq 41^{\circ} \mathrm{C}\right)$ were defined as fever. Data are presented as mean values \pm SD. Asterisks indicate significant differences $\left({ }^{* *} p<0.01\right)$ between infected and control groups

(Fig. 2a). In HP-PRRSV-infected group, piglets exhibited severe gross lesions with consolidation and haemorrhage (Fig. 2b). The parenchymas of the infected lungs were firmer and heavier than those of the control group. The average lung lesion score was significantly higher $(p<0.01)$ than that in the control group (Fig. 2c). 
A

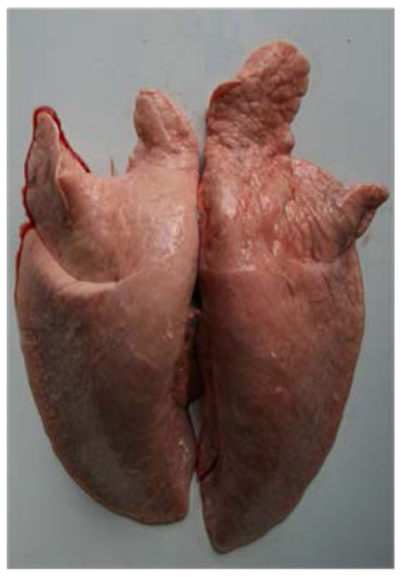

B

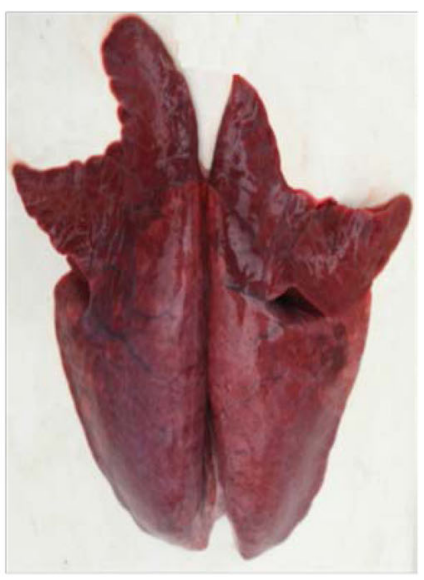

$\star *$

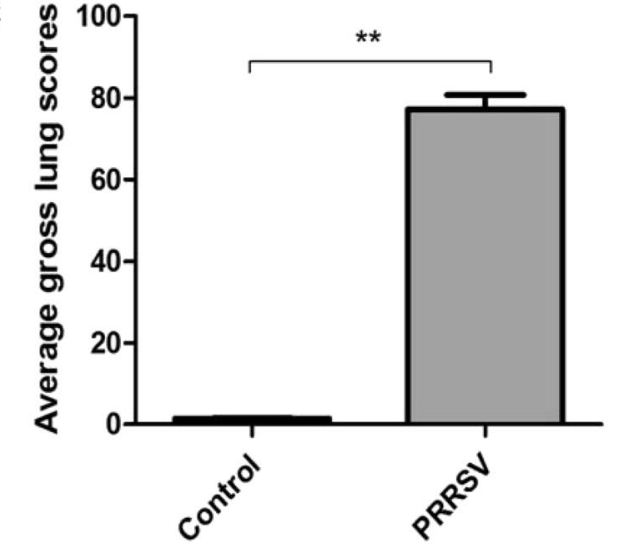

Fig. 2 At necropsy, lungs of the control (a) and HP-PRRSV-infected (b) animals in the study were examined for macroscopic (gross) pathology. The average lung gross scores were evaluated according to the previous scoring system which estimates the percentage of lung affected by pneumonia in the two groups $(n=5)$. The difference of average lung gross scores between lungs of the control and HP-PRRSV-infected animals was presented (c). Data are presented as mean values \pm SD. Asterisks indicate significant differences $\left({ }^{* *} p<0.01\right)$ between infected and control groups

Under histological examination, all the lungs from control piglets did not exhibit any features that are characteristic of acute PRRSV infection (Fig. 3a). However, the lung tissues collected from PRRSV-infected ones developed interstitial pneumonia with alveolar septa thickened by the infiltration of macrophages and lymphomononuclear cells (Fig. 3b).

\section{Leukocyte (white blood cell) count and antibody detection}

The average leukocyte levels during the study are shown in Fig. 4a. Piglets infected with HP-PRRSV TJ strain showed a sharp decrease in white blood cell counts (WBC) on $3 \mathrm{dpi}$, and reached the lowest level at $7 \mathrm{dpi}$. Then WBC developed a tendency to increase thereafter till $14 \mathrm{dpi}$. On $21 \mathrm{dpi}$, WBC level of the survival one returned to the normal level. In contrast, the WBC level in control group did not show significant change during the course of the experiment (Fig. 4a).
Antibody specific for PRRSV was first demonstrated by ELISA on $3 \mathrm{dpi}$ in the infected group and increased gradually. However, ELISA antibody level showed a decline tendency after peak at $14 \mathrm{dpi}$. Low S/P ratio can be detected when animals died of infection, with the exception that the surviving one still showed a detectable titre when the experiment terminated. On the contrary, no detectable ELISA titre can be observed throughout the experiment in the control group (Fig. 4b).

\section{Alterations of peripheral T-lymphocyte subpopulations}

To investigate the influence of HP-PRRSV infection on peripheral blood $\mathrm{T}$ lymphocytes, T-lymphocyte subsets were evaluated using flow cytometry analysis. Before inoculation with the HP-PRRSV TJ strain, there was about $60 \% \mathrm{CD}^{+} \mathrm{T}$ - lymphocytes in the peripheral blood monouclear cells (PBMC) of piglets. As shown in Fig. 5a, the percentage of $\mathrm{CD}^{+}$cells significantly decreased at 3 $(p<0.05)$ and $7 \mathrm{dpi}(p<0.01)$, and returned to the similar level as before infection at 10 and $14 \mathrm{dpi}$. However, 

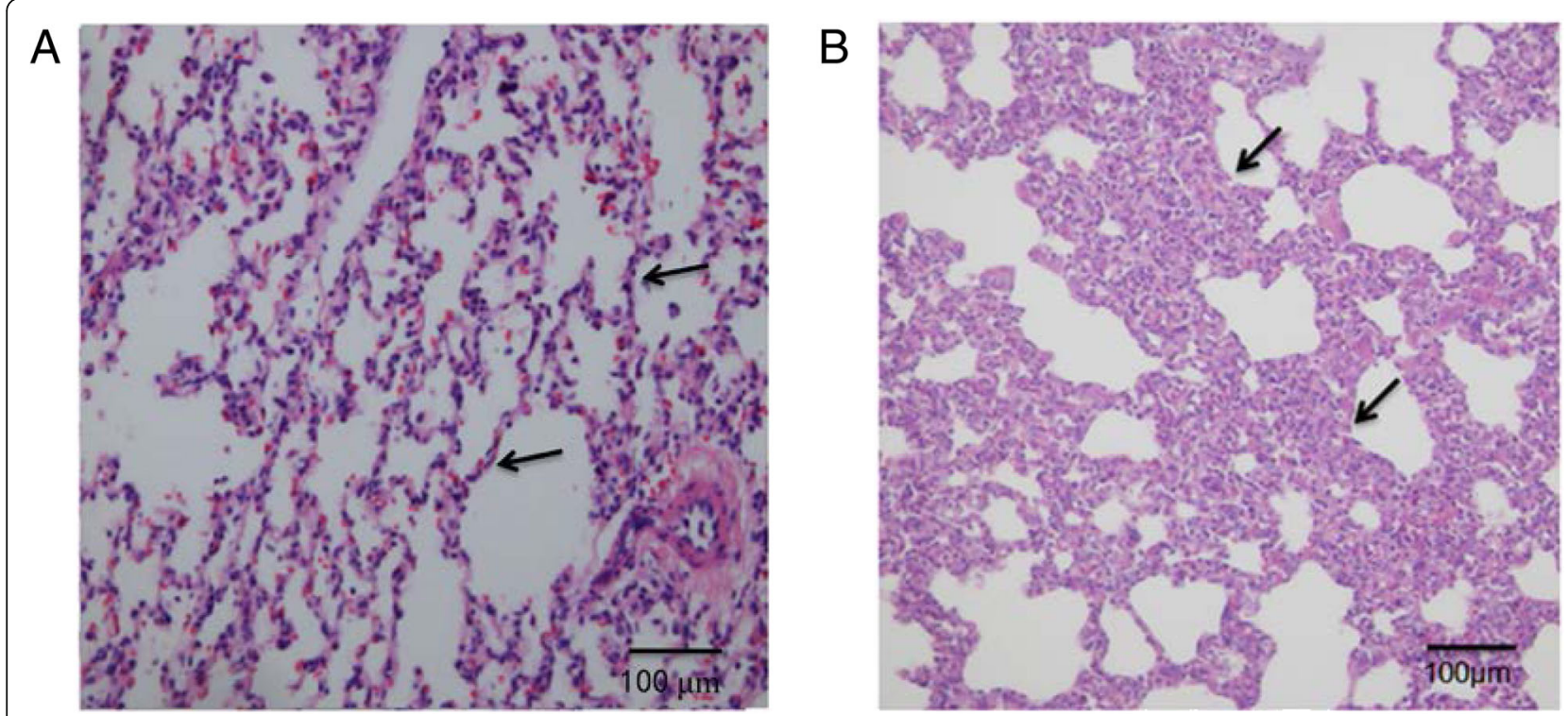

Fig. 3 Histopathological lesions of the lung from HP-PRRSV infected and control piglets. At necropsy, lung samples were collected and processed for histopathology examination following hematoxylin and eosin (H\&E) staining. Lungs of piglets infected with HP-PRRSV (b) showed severe interstitial pneumonia with thickened the alveolar septa (marked with arrows) accompanied by significant infiltration of mononuclear cells, compared to the lungs of negative control piglets (a)

the number of $\mathrm{CD}^{+}$cells showed dramatic decline when animals died of disease $(p<0.01)$. No significant change was detected for $\mathrm{CD}^{+}$cells in the control group (Fig. 5a).

As shown in Fig. 5b, there was about $35 \% \mathrm{CD}^{+} \mathrm{T}$ lymphocyte in the PBMC of infected animals. Then the percentage sharply declined to about $22.7 \%$ at $3 \mathrm{dpi}$ and $15 \%$ at 7 dpi. Interestingly, the proportion of $\mathrm{CD}^{+}$cells remained at a low level until $18 \mathrm{dpi}$ in the PRRSV-infected group. Only the surviving one showed a normal level of $\mathrm{CD}^{+}$cells at $21 \mathrm{dpi}$. On the contrary, the control group remained unchanged throughout the experiment.

There was no significant difference of $\mathrm{CD}^{+}$cells in the control animals. As shown in Fig. 5c, there was about $19.4 \% \mathrm{CD}^{+} \mathrm{T}$ lymphocytes in $\mathrm{PBMC}$ prior to PRRSV infection. However, a transient decrease was observed at $3 \mathrm{dpi}$. Then there was a gradual increase in the percentage of $\mathrm{CD}^{+}$cells at 7-14 dpi. Finally, a slight decrease in the number of $\mathrm{CD}^{+} \mathrm{T}$ lymphocytes occured at $18 \mathrm{dpi}$, which is still higher than the normal level.

Figure $5 \mathrm{~d}$ showed the $\mathrm{CD} 4^{+} / \mathrm{CD}^{+}$values in the both groups. The value kept about 1.5 during the study in the control animals. Similarly, in the infected group, the $\mathrm{CD}^{+} / \mathrm{CD}^{+}$value remained unchanged at $3 \mathrm{dpi}$. Nevertheless, the value significantly declined to about 0.6 at 7 dpi and peeked about 0.4 at $10 \mathrm{dpi}$ and remained at a low level until $18 \mathrm{dpi}$ in the PRRSV-infected group. Only the surviving one showed a normal $\mathrm{CD} 4^{+} / \mathrm{CD}^{+}$ value at $21 \mathrm{dpi}$.

\section{Discussion}

PRRS has been a widespread disease in most pigproducing countries since its first emergence two decades ago in the USA [18]. Current studies have indicated that the emergence and epidemic of highly pathogenic PRRSV not only further aggravates the complicated situation of PRRS infection, but also enhances the genetic diversity of PRRSV in China [19]. Since its emergence in 2006, the HP-PRRS has been devastating in China's swine industry. In current study, the newly isolated PRRSV TJ strain was used to experimentally infect piglets and reproduce the disease symptoms in which the clinical signs and mortality were virtually identical to what was seen in the field. The classical PRRS strains induce abortions in pregnant pigs, transient fever, depression and dyspnoea in male and young pigs [4]. Newborn piglets may die, but the mortality rate is generally low in growing pigs. It is intriguing that the new type of PRRSV that recently emerged in China exhibits unusually high mortality in affected pigs of all ages including adults. The pathogenesis of HP-PRRSV needs to be studied in detail in comparison to classical PRRS strains.

Previous studies demonstrated that HP-PRRSV infected pigs exhibited severe clinical symptoms including persistent high fever, red coloration of body, cyanopathy of ears, conjunctivitis, dyspnoea and severe diffuse pulmonary consolidation lesions [20,21]. Pigs demonstrated significantly reduced numbers of pulmonary alveolar macrophages and peripheral blood monocytes, delayed 


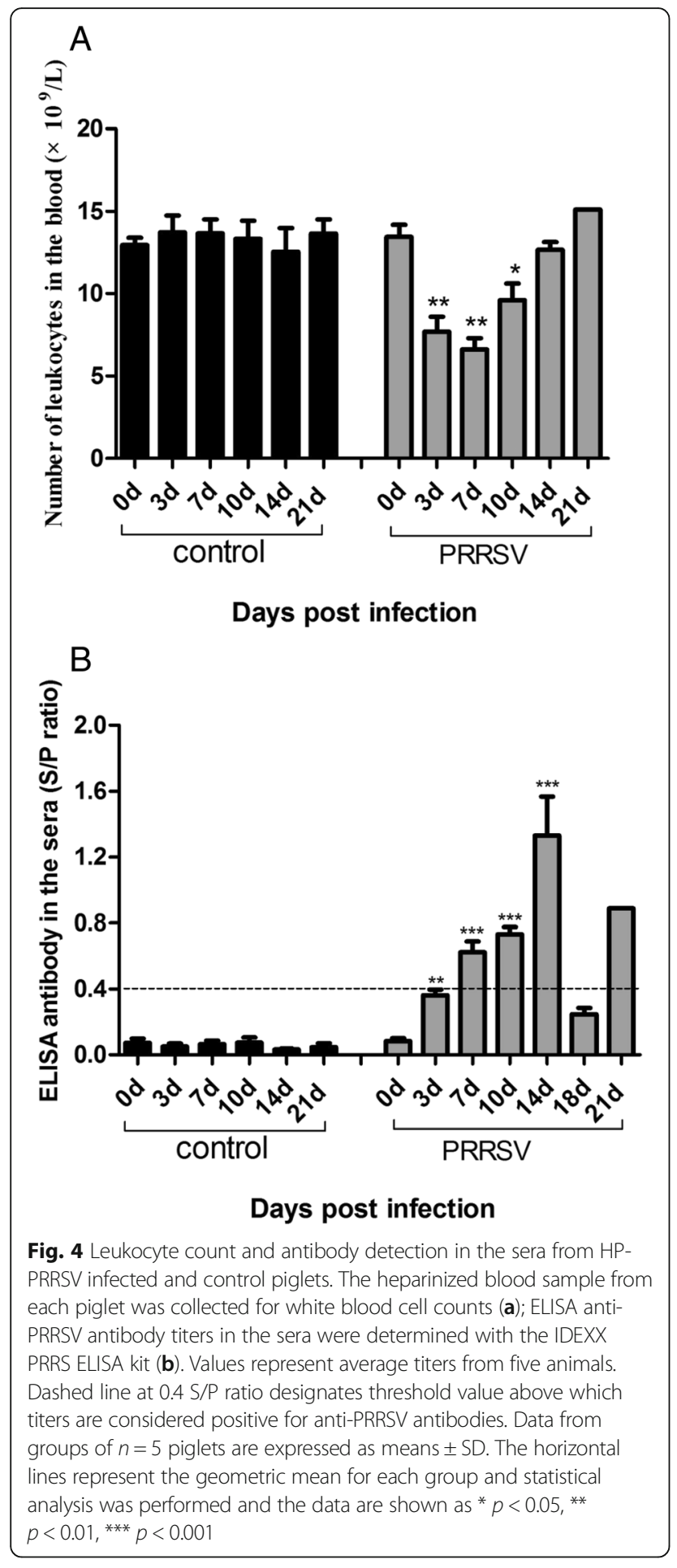

neutralizing and non-neutralizing antibody response after PRRSV infection [22-26]. Piglets infected with HPPRRSV TJ strain in our study developed the typical highly virulent PRRS clinical symptoms reported before. The number of white blood cell counts (WBC) sharply decreased at $3 \mathrm{dpi}$ and peaked at $7 \mathrm{dpi}$ post infection, even though it returned to increase thereafter.
During acute PRRSV infection, pigs developed significantly reduced humoral immune response to classical swine fever modified-live virus vaccine [27]. The immunosuppressive effects are most potent one week after PRRSV infection [28]. It is commonly speculated that HP-PRRSV strains and classical PRRSV strains have similarly destructive effects on the immune system. In present study, the fact that antibody specific for PRRSV was first demonstrated by ELISA at $3 \mathrm{dpi}$ indicated that host humoral immune response was activated at the early period post infection. However, ELISA antibody level showed a dramatic decline after peak at $14 \mathrm{dpi}$. Undetectable $\mathrm{S} / \mathrm{P}$ ratio was observed when animals died of disease, which indicated that host humoral immune response may be suppressed by PRRSV infection.

The present study reported the changes of subpopulations of T-lymphocytes in the HP-PRRSV challenged piglets. Pigs were reported to have transient lymphocytopenia of $\mathrm{CD}_{4}^{+} \mathrm{CD}^{-}$and $\mathrm{CD} 4{ }^{-} \mathrm{CD}^{+} \mathrm{T}$ cells from three days to approximately four weeks after PRRSV infection [29-31]. The T-cell responses to PRRSV are induced 28 weeks post-infection $[32,33]$. In our study, the percentages of $\mathrm{CD}^{+} \mathrm{T}$ lymphocytes subsets in the PBMCs and $\mathrm{CD} 8^{+}$cells in the $\mathrm{T}$ lymphocytes both significantly decreased at 3 and/or $7 \mathrm{dpi}$, then had a tendency to increase until $14 \mathrm{dpi}$. Similarly, both of $\mathrm{CD}^{+}$and CD8 + cells declined to the low level at $18 \mathrm{dpi}$ when animals died of disease. These results are consistent with Shimizu's report that total lymphocytes, $\mathrm{CD}^{+}$cells decreased after PRRS virus infected [31]. Nevertheless, contradictory results showed that restimulation with PRRSV of PBMC derived from PRRSV infected pigs in vitro resulted in an increased percentage of CD3 ${ }^{+} \mathrm{CD} 8{ }^{\text {high }}$ cells starting from $14 \mathrm{dpi}$ compared to mock-restimulation. On the other hand, the number of $\mathrm{CD}^{+}$and $\mathrm{CD}^{+} / \mathrm{CD}^{+}$value showed a similar tendency throughout the experiment period. They both decreased from $3 \mathrm{dpi}$ to $7 \mathrm{dpi}$ and remained the low level before animal died. Interestingly, all the $\mathrm{T}$ lymphocytes of the surviving one returned to normal level in the end of the study. These findings agreed with the Shimizu's study. In contrast, previous study demonstrated that PRRSV increased the number of $\mathrm{CD} 4^{+} \mathrm{CD}^{+} \mathrm{CD}^{2} 5^{+} \mathrm{Foxp}^{+}$cells at $14 \mathrm{dpi}$, whereas CD4 ${ }^{+} \mathrm{CD} 8^{-} \mathrm{CD} 25^{+} \mathrm{Foxp}^{+}$remained constant until $28 \mathrm{dpi}$ [34]. In our study, $\mathrm{CD} 4^{+} \mathrm{CD}^{+}$cells showed a transient increase from 1 to $3 \mathrm{dpi}$, though it returned to low level afterward (data not shown).

Results from this study suggest that HP-PRRSV TJ strain has more seriously destructive effects on the immune system than classical PRRSV strains, and induces seriously poor adaptive immune responses on the piglets, and facilitates the invasion of other pathogens. 


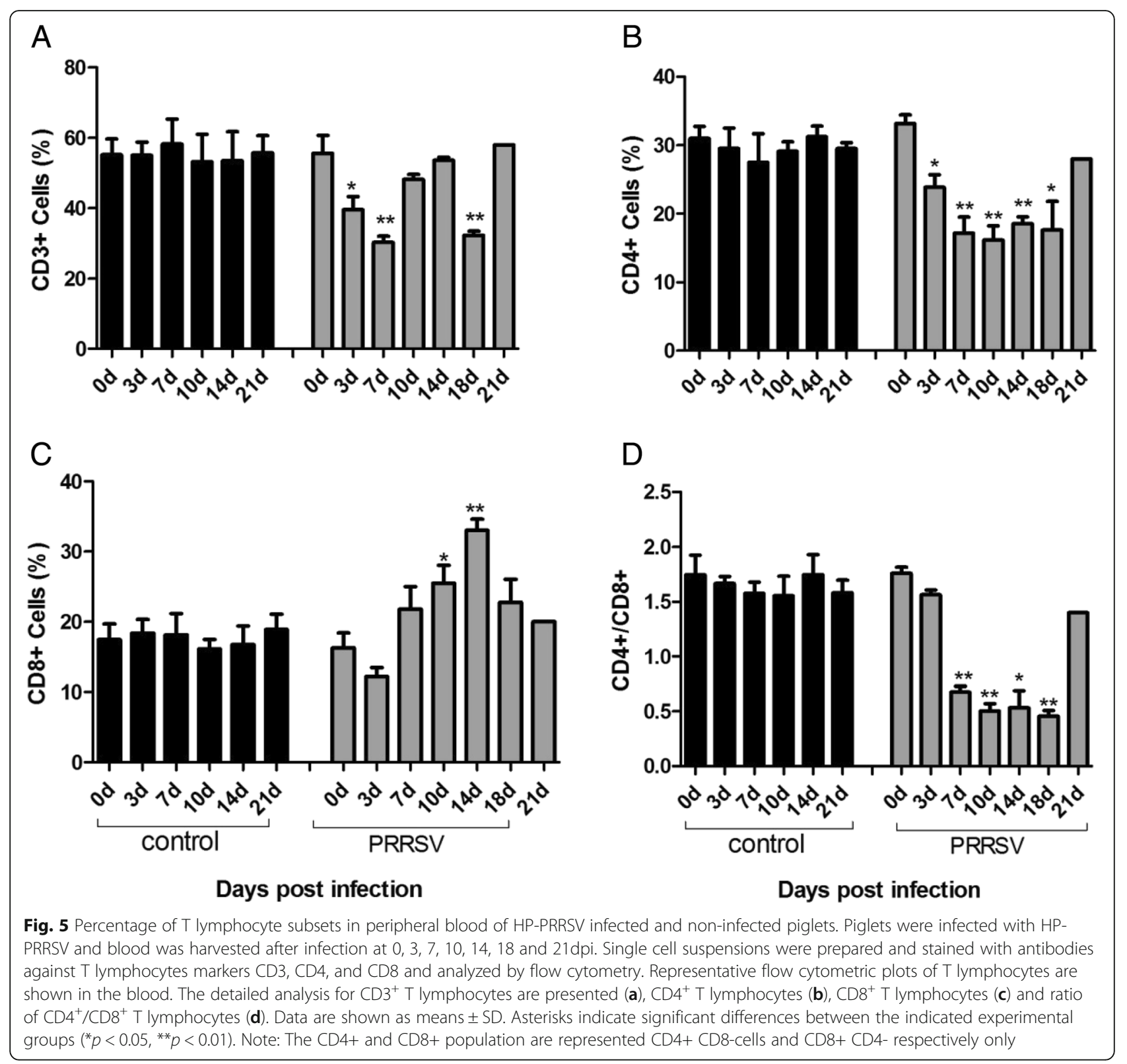

\section{Conclusions}

In this study, the experimental infection with HPPRRSV TJ strain has reproduced the disease of high virulence and high mortality compared to the clinical signs seen in classical PRRS. It is indicated that HPPRRSV TJ strain infection would activate host humoral immune response at the early period post infection and cause severe pathological damages on lungs and inhibit cellular immune response after infection.

However, comparison of pathogenesis between HPPRRSV and LP-PRRSV infection need to be further investigated.

\section{Methods}

Cells, antibodies and viruses

The MARC-145 cell line (derived from African green monkey kidney cells) was employed for viral propagation and titration. MARC-145 cells were maintained in minimum essential medium (MEM) supplemented with $8 \%$ fetal bovine serum (FBS, Hyclone Laboratories Inc, South Logan, UT, USA) at $37{ }^{\circ} \mathrm{C}$, with $5 \%$ CO2. PRRSV strain TJ (GenBank accession no. EU860248) was isolated and maintained in our laboratory as previously described [35]. Antibodies used for flow cytometric analysis, such as anti-CD3 (PE/ Cy5-conjugated MAb PPT3), anti-CD4 (PE-conjugated 
MAb 74-12-4), and anti-CD8 (FITC-conjugated MAb 762-11) were purchased from BD Pharmingen (San Jose, CA).

\section{Animals and experimental design}

Ten healthy crossbred piglets from a PRRSV-free herd were obtained, weaned, and transported to the biological safety level 2 (BSL2) facilities at the Teyan Veterinary Biologic Factory at three weeks of age. All animals were confirmed to be free of PRRSV, CSFV, PRV, SIV, Mycoplasma hyopneumoniae, and PCV2 infections using methods previously described (Leng et al. [13]). Weaned piglets were collectively housed for several days prior to exposure to virus, and then individually housed in the isolation units from the time of exposure until the end of the observation period. Ten piglets were randomly divided into two groups. Piglets of group $1(n=5)$ were inoculated intranasally (i.n.) with $10^{3.0} 50 \%$ tissue culture infective doses $\left(\mathrm{TCID}_{50}\right)$ of PRRSV TJ strain. Group 2 $(n=5)$ was inoculated intranasally with supernatant of lysate of MARC-145 cells in a 1-mL volume. All experimental procedures have been reviewed and approved by local Animal Care \& Use Committee of Institute of Special Wild Economic Animal and Plant Sciences, Chinese Academy of Agricultural Sciences, Jilin, China.

\section{Clinical observation and sample collection}

After infection, animals were monitored twice daily for clinical signs, including depression, anorexia, diarrhea, skin discolorations, conjunctivitis, lameness, coughing, labored and abdominal breathing and respiratory rate. Rectal temperatures were recorded every day throughout the experiment. Clinical signs and food intake were evaluated daily for each animal in both groups. Clinical signs were observed and graded using a scoring system described previously [36], which is shown in Table 1 . Blood samples with and without heparin were collected on $0,3,7,10$ and 14 days post-infection (dpi). Heparinised blood samples were used to detect $\mathrm{CD}^{+}, \mathrm{CD}^{+}$, and $\mathrm{CD} 8^{+} \mathrm{T}$ lymphocytes and white blood cell counts. Serum samples were used to measure the ELISA antibody titers against PRRSV. All the animals were euthanized at day $21 \mathrm{dpi}$.

\section{Serological examination}

PRRSV-specific antibody responses were analyzed with serum collected at $0,3,7,10,14$ and $21 \mathrm{dpi}$, using a commercial ELISA kit (Idexx Laboratories Inc., Westbrook, ME) according to the manufacturer's instructions. The PRRSV-specific antibody level was reported as an S/ $P$ ratio, and the serum samples were considered positive if the $\mathrm{S} / \mathrm{P}$ ratio was 0.4 or higher.
Table 1 Scores assigned to clinical signs observed in pigs following inoculation of HP-PRRSV

\begin{tabular}{lll}
\hline Category of clinical sign & Symptom & Score \\
\hline Systemic: & Normal & 0 \\
& Apathy & 1 \\
& Anorexia & 2 \\
& Severe depression & 5 \\
& Death & 10 \\
Respiratory: & Normal & 0 \\
& Sneezing, Coughing & 1 \\
& Tachypnea & 2 \\
& Laboured breathing & 3 \\
& Abdominal breathing & 5 \\
Other symptoms: & Normal & 0 \\
& Diarrhea, & 1 \\
& Conjunctivitis & 2 \\
& Reddening of the ears & 3 \\
& Skin cyanopathy & 5 \\
\hline
\end{tabular}

Gross pathology and histological evaluations of lungs At necropsy, lungs of the animals in the study were examined for macroscopic (gross) pathology, lungs were evaluated and graded using an established scoring system which estimates the percentage of lung affected by pneumonia. On the other hand, lung samples were collected and processed for histopathology examination following hematoxylin and eosin (H\&E) staining, as described previously \23].

\section{Leukocyte (white blood cell) counts}

Heparinised blood was collected and the leukocyte (white blood cell) counts were determined using an automatic analyzer CA 500 (Sysmex CA-500 automated blood coagulation analyzer, Japan) according to the manufacturer's instructions.

\section{Flow cytometry analysis}

Blood was collected and red blood cells were lysed with ACK lysis buffer (BioSource International, Inc., Camarillo, CA) for $1 \mathrm{~min}$ at room temperature. Single-cell suspensions (at 106 cells) were prepared in Hanks balanced salt solution (HBSS) (Invitrogen) and stained with antibodies against CD3, CD4, CD8 (BD PharMingen). After incubation on ice for $30 \mathrm{~min}$, cells were washed twice in PBS containing $2 \%$ FBS and $0.02 \%$ NaN3. Then the cells were fixed with $1 \%$ paraformaldehyde. Data collection and analysis were performed with a BD LSR-II flow cytometer, BD FACSDiva software (BD Pharmingen), FlowJo software (TreeStar, San Carlos, CA), Prism software, and Microsoft Excel (Seattle, WA). 


\section{Statistical analyses}

The significant differences of the in vitro experiment and animal trials were analyzed using a one-way or twoway ANOVA in the GraphPad Prism (version 5.0) software. A $t$-test or F-test was used to estimate the variability among the gross lesion, leukocyte count, antibody level and flow cytometry results. Differences were considered statistically significant at a $P$ value of $<0.05$ and extremely significant at a value of $P<0.01$ or $P<0.001$.

\section{Abbreviations}

BSL2: biological safety level 2; dpi: days post-infection; FBS: fetal bovine serum; FCM: flow cytometry; H\&E: Hematoxylin and eosin; HP-PRRSV: Highly pathogenic porcine reproductive and respiratory syndrome virus; MEM: Maintained in minimum essential medium; PBMC: Peripheral blood monouclear cells; PRRSV: Porcine reproductive and respiratory syndrome virus; $\mathrm{TCID}_{50}$ : Tissue culture infective doses; WBC: White blood cells count

\section{Acknowledgements}

We are grateful of Dr. Wenzhi Xue for many helpful suggestions and his critical reading of the manuscript. We also would like to thank Dr. Xuejin Su from Norman Bethune University of Medical Science for the help in the flow cytometry analysis.

\section{Funding}

The study was financially supported by the JILIN Science and Technology Development Plan (201505200125JH) and JILIN province project for transformation of scientific and technological achievements (20140307008NY), Technology Innovation Program from Chinese Academy of Agricultural Sciences (20140204066NY) .

\section{Availability of data and materials}

All row data are available in State Key Laboratory of Special Economic Animal Molecular Biology, Institute of Special Economic Animal and Plant Sciences, Chinese Academy of Agricultural Sciences, China upon official request via mail (lizhenguang@caas.cn).

\section{Authors' contributions}

ZGL and YLH participated in the design of the study, performed the experiments and drafted the manuscript. XQX, SFL helped with the animal experiment. $\mathrm{XL}$ and MQX helped with the flow cytometry. YJW, FXW performed the statistical analysis. HW and SPC conceived the study and participated in its design and coordination. All authors read and approved the final manuscript.

\section{Competing interests}

The authors declare that they have no competing interests.

\section{Consent for publication}

Not applicable.

\section{Ethics approval and consent to participate}

All experimental procedures have been reviewed and approved by local Animal Care \& Use Committee of Institute of Special Economic Animal and Plant Sciences, Chinese Academy of Agricultural Sciences, Jilin, China (Approval number. SEAPS-IACUC-2016-012). And we have followed the 3 Rs guiding principles during the course of animal experiment.

\section{Consent from client owned animal}

Animal experiment and sample collection were obtained the consent from farm owner and approved ethically by local ethics committee of Institute of Special Wild Economic Animal and Plant Sciences, Chinese Academy of Agricultural Sciences, Jilin, China.

\section{Author details}

${ }^{1}$ Sinovet (Beijing) Biotechnology Co., Ltd., Kaituo Road 5, Haidian District, Beijing 100085, China. ${ }^{2}$ State Key Laboratory of Special Economic Animal Molecular Biology, Institute of Special Economic Animal and Plant Sciences,
Chinese Academy of Agricultural Sciences ", Juye Street 4899, Changchun, Jilin 130122, China. ${ }^{3}$ Jiangyan Animal Health Inspection Institute, Jiangguan Road 251, Taizhou, Jiangsu 225529, China.

Received: 26 August 2015 Accepted: 4 October 2016

Published online: 12 October 2016

\section{References}

1. Rossow KD. Porcine reproductive and respiratory syndrome. Vet Pathol. 1998;35(1):1-20

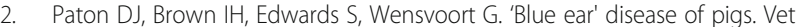
Rec. 1991;128(26):617.

3. Cavanagh D. Nidovirales: a new order comprising Coronaviridae and Arteriviridae. Arch Virol. 1997;142(3):629-33.

4. Gomez-Laguna J, Salguero FJ, Pallares FJ, Carrasco L. Immunopathogenesis of porcine reproductive and respiratory syndrome in the respiratory tract of pigs. Vet J. 2013;195(2):148-55.

5. Wills RW, Zimmerman JJ, Yoon KJ, Swenson SL, Hoffman LJ, McGinley MJ, Hill HT, Platt KB. Porcine reproductive and respiratory syndrome virus: routes of excretion. Vet Microbiol. 1997:57(1):69-81.

6. Rowland RR, Lawson S, Rossow K, Benfield DA. Lymphoid tissue tropism of porcine reproductive and respiratory syndrome virus replication during persistent infection of pigs originally exposed to virus in utero. Vet Microbiol. 2003:96(3):219-35.

7. Bilodeau R, Archambault D, Vezina SA, Sauvageau R, Fournier M, Dea S. Persistence of porcine reproductive and respiratory syndrome virus infection in a swine operation. Can J Vet Res. 1994;58(4):291-8.

8. Rowland RR, Kervin R, Kuckleburg C, Sperlich A, Benfield DA. The localization of porcine reproductive and respiratory syndrome virus nucleocapsid protein to the nucleolus of infected cells and identification of a potential nucleolar localization signal sequence. Virus Res. 1999;64(1):1-12.

9. Neumann EJ, Kliebenstein JB, Johnson CD, Mabry JW, Bush EJ, Seitzinger $\mathrm{AH}$, Green AL, Zimmerman JJ. Assessment of the economic impact of porcine reproductive and respiratory syndrome on swine production in the United States. J Am Vet Med Assoc. 2005;227(3):385-92.

10. Li Y, Wang $X$, Bo K, Tang B, Yang B, Jiang W, Jiang P. Emergence of a highly pathogenic porcine reproductive and respiratory syndrome virus in the Mid-Eastern region of China. Vet J. 2007:174(3):577-84.

11. Tian K, Yu X, Zhao T, Feng Y, Cao Z, Wang C, Hu Y, Chen X, Hu D, Tian X, et al. Emergence of fatal PRRSV variants: unparalleled outbreaks of atypical PRRS in China and molecular dissection of the unique hallmark. PLoS One. 2007;2(6), e526.

12. Tong GZ, Zhou YJ, Hao XF, Tian ZJ, An TQ, Qiu HJ. Highly pathogenic porcine reproductive and respiratory syndrome. China Emerg Infect Dis. 2007;13(9):1434-6.

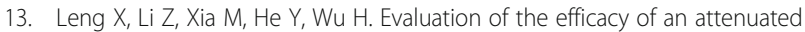
live vaccine against highly pathogenic porcine reproductive and respiratory syndrome virus in young pigs. Clinical and vaccine immunology : CVI. 2012; 19(8):1199-206.

14. Albina E, Carrat C, Charley B. Interferon-alpha response to swine arterivirus (PoAV), the porcine reproductive and respiratory syndrome virus. J Interferon Cytokine Res. 1998;18(7):485-90.

15. Lopez OJ, Osorio FA. Role of neutralizing antibodies in PRRSV protective immunity. Vet Immunol Immunopathol. 2004;102(3):155-63.

16. Meier WA, Galeota J, Osorio FA, Husmann RJ, Schnitzlein WM, Zuckermann FA. Gradual development of the interferon-gamma response of swine to porcine reproductive and respiratory syndrome virus infection or vaccination. Virology. 2003;309(1):18-31.

17. Beura LK, Sarkar SN, Kwon B, Subramaniam S, Jones C, Pattnaik AK, Osorio FA. Porcine reproductive and respiratory syndrome virus nonstructural protein 1 beta modulates host innate immune response by antagonizing IRF3 activation. J Virol. 2010;84(3):1574-84.

18. Albina E. Epidemiology of porcine reproductive and respiratory syndrome (PRRS): an overview. Vet Microbiol. 1997;55(1-4):309-16.

19. Zhou L, Yang H. Porcine reproductive and respiratory syndrome in China. Virus Res. 2010:154(1-2):31-7.

20. Feng $Y$, Zhao T, Nguyen T, Inui $K$, Ma Y, Nguyen TH, Nguyen VC, Liu D, Bu $\mathrm{QA}$, To LT, et al. Porcine respiratory and reproductive syndrome virus variants, Vietnam and China, 2007. Emerg Infect Dis. 2008;14(11):1774-6. 
21. Zhou YJ, Hao XF, Tian ZJ, Tong GZ, Yoo D, An TQ, Zhou T, Li GX, Qiu HJ, Wei TC, et al. Highly virulent porcine reproductive and respiratory syndrome virus emerged in China. Transbound Emerg Dis. 2008;55(3-4):152-64.

22. Rossow KD, Bautista EM, Goyal SM, Molitor TW, Murtaugh MP, Morrison RB, Benfield DA, Collins JE. Experimental porcine reproductive and respiratory syndrome virus infection in one-, four-, and 10-week-old pigs. J Vet Diagn Invest. 1994;6(1):3-12.

23. Halbur PG, Paul PS, Frey ML, Landgraf J, Eernisse K, Meng XJ, Lum MA, Andrews JJ, Rathje JA. Comparison of the pathogenicity of two US porcine reproductive and respiratory syndrome virus isolates with that of the Lelystad virus. Vet Pathol. 1995;32(6):648-60.

24. Halbur PG, Paul PS, Meng XJ, Lum MA, Andrews JJ, Rathje JA. Comparative pathogenicity of nine US porcine reproductive and respiratory syndrome virus (PRRSV) isolates in a five-week-old cesarean-derived, colostrumdeprived pig model. J Vet Diagn Invest. 1996;8(1):11-20.

25. Done SH, Paton DJ. Porcine reproductive and respiratory syndrome: clinical disease, pathology and immunosuppression. Vet Rec. 1995;136(2):32-5.

26. Charerntantanakul W, Platt R, Johnson W, Roof M, Vaughn E, Roth JA. Immune responses and protection by vaccine and various vaccine adjuvant candidates to virulent porcine reproductive and respiratory syndrome virus. Vet Immunol Immunopathol. 2006;109(1-2):99-115.

27. Suradhat S, Kesdangsakonwut S, Sada W, Buranapraditkun S, Wongsawang $S$, Thanawongnuwech R. Negative impact of porcine reproductive and respiratory syndrome virus infection on the efficacy of classical swine fever vaccine. Vaccine. 2006;24(14):2634-42.

28. Thanawongnuwech R, Brown GB, Halbur PG, Roth JA, Royer RL, Thacker BJ. Pathogenesis of porcine reproductive and respiratory syndrome virusinduced increase in susceptibility to Streptococcus suis infection. Vet Pathol. 2000;37(2):143-52.

29. Lamontagne L, Page C, Larochelle R, Magar R. Porcine reproductive and respiratory syndrome virus persistence in blood, spleen, lymph nodes, and tonsils of experimentally infected pigs depends on the level of CD8high T cells. Viral Immunol. 2003;16(3):395-406.

30. Samsom JN, de Bruin TG, Voermans JJ, Meulenberg JJ, Pol JM, Bianchi AT. Changes of leukocyte phenotype and function in the broncho-alveolar lavage fluid of pigs infected with porcine reproductive and respiratory syndrome virus: a role for CD8(+) cells. J Gen Virol. 2000;81(Pt 2):497-505.

31. Shimizu M, Yamada S, Kawashima K, Ohashi S, Shimizu S, Ogawa T. Changes of lymphocyte subpopulations in pigs infected with porcine reproductive and respiratory syndrome (PRRS) virus. Vet Immunol Immunopathol. 1996;50(1-2):19-27.

32. Xiao Z, Batista L, Dee S, Halbur P, Murtaugh MP. The level of virusspecific T-cell and macrophage recruitment in porcine reproductive and respiratory syndrome virus infection in pigs is independent of virus load. J Virol. 2004;78(11):5923-33.

33. Bautista EM, Molitor TW. Cell-mediated immunity to porcine reproductive and respiratory syndrome virus in swine. Viral Immunol. 1997;10(2):83-94.

34. Silva-Campa E, Mata-Haro V, Mateu E, Hernandez J. Porcine reproductive and respiratory syndrome virus induces CD4 + CD8 + CD25 + Foxp3+ regulatory T cells (Tregs). Virology. 2012;430(1):73-80.

35. Xue Leng, Zhenguang Li, Mingqi Xia, Xiyu Li, Fengxue Wang, Wei Wang, Xiuhua Zhang, Hua Wu, Xue Leng, Zhenguang Li, Mingqi Xia, Xiyu Li, Fengxue Wang, Wei Wang, Xiuhua Zhang, Hua Wu. Mutations in the genome of the highly pathogenic porcine reproductive and respiratory syndrome virus potentially related to attenuation. Veterinary Microbiology. 2012;157(1-2):50-60

36 Prieto C, Martinez-Lobo FJ, Diez-Fuertes F, Aguilar-Calvo P, Simarro I, Castro $\mathrm{JM}$. Immunisation of pigs with a major envelope protein sub-unit vaccine against porcine reproductive and respiratory syndrome virus (PRRSV) results in enhanced clinical disease following experimental challenge. Vet J. 2011; 189(3):323-9.

\section{Submit your next manuscript to BioMed Central and we will help you at every step:}

- We accept pre-submission inquiries

- Our selector tool helps you to find the most relevant journal

- We provide round the clock customer support

- Convenient online submission

- Thorough peer review

- Inclusion in PubMed and all major indexing services

- Maximum visibility for your research

Submit your manuscript at www.biomedcentral.com/submit
() BioMed Central 